\title{
Child Abuse by Parents and Its Influence on the Development of Juvenile Delinquency \\ Tatjana Vujović1
}

\begin{abstract}
The study was focused on parental acceptance/rejection experienced during childhood, as well as its influence on the later delinquent behaviour. We tried to answer which particular instances of parental behaviour differentiate juvenile delinquents from lawabiding adolescents. The starting point for this research was Rohner Parental acceptance-rejection theory (PARTheory). We aimed to test the hypothesis that perceived rejection has a strong impact on the development of an aberrant behaviour in children. The research was carried out on a sample of 265 adolescents composing 2 independent groups: one consisted of 115 under-age delinquents (experimental), and the other included 150 lawabiding adolescents (control). Basing on the results of examination of the parental behaviour, we found that these two groups had more differences than similarities. Father's neglect was proved to be the major difference beetween the groups. Besides that, significant differentiating factors were: manipulativity (verbal aggression) and physical abuse of the children (both parents).
\end{abstract}

Keywords: juvenile delinquents, aggression, emotional neglect.

\section{Introduction}

Child abuse and neglect are the worst kind of abnormal relationships between child and parents. Cumulative effect of the repeating episodes of abuse has a significant negative influence on child development.

In developed contries child abuse and neglect were systemically studied for last 20 years, and ample data have been accumulated by now. Meanwhile, in Montenegro these issues remain poorly studied. There are several research works on child abuse and neglect (Stojaković, 1984; Milosavljević, 1997; Banjanin-Đuričić, 1998), but even these studies are more focused on the phenomena itself, than on the characteristics of parents abusing their children.

\footnotetext{
${ }^{1}$ Faculty of Philosophy Nikšić, The University of Montenegro, Montenegro.
} 
Experimental data confirm the relationship between parental abuse in early childhood and psychosocial problems in adolescense and adulthood. Physical and sexual abuse as well as child neglect are tightly associated with the high risk of manifestation of various internalizing and externalizing behavioural problems in adolescence (Flisher et al.., 1997; Finkelhore, 1995; Vujović, 2005). Physical abuse in early childhood is known to be highly predictive for antisocial behaviour in adolescence. The study (Vujović, 2006) conducted on the sample of 265 adolescents, 115 under-aged delinquents, and 150 successfully socialized adolescents showed that in the majority of cases under-aged delinquents percieved their parents as physically agressive and emotionally cold. Forty (34.8\%) of 115 under-aged delinquents experienced (reported) physical abuse from the side of the father very often, 31 (27\%) often, 10 (8.7\%) sometimes, 19 (16.5\%) rarely, and $15(13 \%)$ never.

Although sexual abuse in the childhood might cause behavioural disorders in adolescence, it is significantly associated with a number of developmental problems (symptoms of agression and psychopathology are not included), while antisocial behaviour is more typical consequence of physical abuse. Both kinds of abuse in early childhood may result in various emotional disorders in adolescence, such as, for example, depression. It was previously found that physical abuse and depression have interaction effect: these factors in combination, but not individually, determine the high risk of agression (Scerbo, Kolko, 1995). Very often child abuse and neglect lead to manifestation of selfdestructive behaviour, suicide ideation and attempts, and different types of selfmutilation.

Considerable progress in understanding of influence of child abuse by parents on delinquent behaviour formation in adolescence was previously attained by several authors. In research of risk factors in psychopathology development in adolescence Zaenah et al.. (1997) found that poverty and financial straits significantly increase the risk of emotional problems and increase psychological vulnerability of parents under the conditions of negative life experiences (Ja bih rekla ovdje - "decrease psychological resilience of the parents"). Their relationships with their children also change: rejection in the form of physical abuse takes place, while the capacity to emotionally support and show acceptance in stress situations is significantly decreased.

Child abuse is not highly specific risk factor for aggressive behaviour in adolescence, since it may cause a number of psychopathological issues, and increased aggression is just one of them. The relations between child abuse/ neglect and aggressive behaviour are more complicated than direct, linear, and causal dependence; they can be characterized as correlational and interactive. Mechanisms mediating risk for aggressive behaviour in abused children include various psychosocial and neurobiological factors. 
Our understanding of this issue was considerably contributed by Rohner's theory of parental acceptance-rejection.

One of the first and still the most influential theories aimed to explain the connection between parental behaviour and psychosocial disorders in adolescents is Rohner's Parental Acceptance and Rejection Theory (PART). This theory is formulated to predict and explain the reasons and consequences of parental behaviour related to the emotional warmth dimension, balancing between acceptance and rejection of the child (Rohner, 1980). According to this theory, parental rejection has strong negative consequences, particularly when observed by the individual, on the behaviour and personality of children as well as on the functioning of an adult who says that he/she was a "rejected" child. Acceptance (love) and rejection (lack of love) are the main predictors of psychosocial development of the children. The theory of parental acceptance-rejection predicts that parental rejection has negative effects on the psychological adjustment and behavioural functioning (children's behaviour). Parental acceptance can be expressed physically (by hugging, kissing, caressing) and verbally (by praising, complimenting, saying nice things to/ about the child). This behaviour and care, support, and attention define the behavioural signatures of parental acceptance. Parental rejection manifests in two ways: aggressive behaviour and neglect. Aggressive parents can express their hostility physically (by hitting the child, pushing, pinching, throwing things) and verbally (through sarcasm, profanity, by ridiculing, shouting at a child, humiliating and insulting a child). Indifferent parents are physically and mentally away from children. They tend to disregard child's physical and emotional needs. Such parents tend to pay little attention to the children and to spend minimum of time with them. They often forget the promises they made to their children, and do not notice any other needs necessary for the development of their children.

Research in the United States confirms that the rejection may get involved in a number of psychiatric disorders and behavioural disorders including: neurosis, schizophrenia, psychosomatic illnesses, allergies, delinquency, problems at school, stuttering, a distorted body image, and so on. Extensive intercultural research during 45 years shows that parental rejection can manifest in four ways: 1 . emotional coldness and insensibility; 2. animosity and aggressiveness; 3. indifference and negligence; 4. undefined rejection (Rohner, 1984). Individuals may subjectively experience parental rejection as undefined rejection. Undefined rejection refers to the feeling that their parents do not love or care about them, when there are not necessarily objective indicators that parents are cold and insensitive, rude and aggressive or indifferent. 
The aim of the research was to study the relations between parental acceptance in early childhood and delinquent behaviour in adolescence. The assessment of different kinds of socially unacceptable behaviour is an important characteristic of the abused child. The question whether this kind of behaviour was the reason or the consequence of abuse is to be answered.

\section{Basic hypotheses of the study are:}

Hypothesis A: It is assumed that the specifics of delinquent's evaluation of parental behaviour will be important to determine the dimensions of parental behaviour, which will have a predictive value for the development of delinquent behaviour.

Hypothesis B: It is supposed that the assessment of parental behaviour in delinquent group and in the group of adolescents with socially acceptable behaviour will significantly differ.

\section{Metods}

\section{Participants}

The research was carried out on 265 participants. All participants were aged from 15 to 18 years old. The study was conducted on two independent representative samples.

Sample of juvenile delinquents (experimental). The survey was conducted on a sample of 115 juvenile delinquents. All the participants were adolescents aged from 15 to 18 . A total of 88 male and 27 female examinees participated in the inquiry. The sample consisted of juvenile delinquents who were registered by the Centre for Social Welfare of the Municipality of Podgorica, as follows: juvenile delinquents who were sentenced to the educational/ corrective measure of increased supervision by the guardianship authority, as well as juvenile delinquents who were subjected to the institutional educational sanctions.

Sample of well-socialized adolescents (control) included 150 participants, all of them were students of 3rd and 4th year of the secondary touristic school "Sergej Stanić" in Podgorica. The sample underwent two-step randomization: first, the school was randomly chosen, and then the school grades ( 3 classes on the 3rd year and 2 classes on the 4th year of education) enrolled in the study were randomly defined. The number of interviewed students was proportional to the total number of students in the school. 


\section{Measuring instrument}

The main research instrument was a questionnaire, which was designed for the large-scale social research in Montenegro. The primary purpose of the survey was to examine the attitudes of juvenile delinquents, that are, in particular, their views and perceptions of being accepted/rejected by parents. As a foundation for the development of the questionnaire the following models were used: Pari (Schaefer \& RQ Bell, 1958), Gradir (Knezevic, 1994). The perception of parental behaviour scale from the questionnaire was used to examine the structure of perceived parents' behaviour (Table 1). The scale consists of 20 questions, and items are arranged in two subscales. The examinee describes how his/her mother or father behaves towards him/her using Likerttype scale with 5 degrees. In this case these modalities were as follows:

Table 1 - Scale of parental behaviour perception used in the research

\begin{tabular}{|c|c|c|c|c|c|}
\hline Scale of parental behaviour perception & $\begin{array}{l}\text { I } \\
\text { agree }\end{array}$ & $\begin{array}{c}\text { I } \\
\text { generally } \\
\text { agree }\end{array}$ & $\begin{array}{l}\text { I am } \\
\text { indecisive }\end{array}$ & $\begin{array}{c}\text { I } \\
\text { generally } \\
\text { disagree }\end{array}$ & $\begin{array}{l}\text { I do not } \\
\text { agre } \\
\text { at all }\end{array}$ \\
\hline \multicolumn{6}{|l|}{ 1. Mother's emotional detachment } \\
\hline \multicolumn{6}{|l|}{ 2. Child unwanted by the mother } \\
\hline \multicolumn{6}{|l|}{ 3. Child as a "burden" to the mother } \\
\hline \multicolumn{6}{|l|}{ 4. Mother's indifference } \\
\hline \multicolumn{6}{|l|}{ 5. Mother's neglect } \\
\hline \multicolumn{6}{|l|}{$\begin{array}{l}\text { 6. Insufficient time dedicated by the father } \\
\text { to the child's play }\end{array}$} \\
\hline \multicolumn{6}{|l|}{ 7. Both parent's play with the child } \\
\hline \multicolumn{6}{|l|}{ 8. Physical abuse by the father } \\
\hline \multicolumn{6}{|l|}{ 9. Father's severity } \\
\hline \multicolumn{6}{|l|}{ 10. Physical abuse by both parents } \\
\hline \multicolumn{6}{|l|}{$\begin{array}{l}\text { 11. Parents' manipulative behaviour towards } \\
\text { the child }\end{array}$} \\
\hline \multicolumn{6}{|l|}{ 12. Father's complaisance } \\
\hline \multicolumn{6}{|l|}{$\begin{array}{l}\text { 13. Abandonment of the child by both parents } \\
\text { during several days }\end{array}$} \\
\hline \multicolumn{6}{|l|}{ 14. Mother's severity } \\
\hline \multicolumn{6}{|l|}{ 15. Mother's complaisance } \\
\hline \multicolumn{6}{|l|}{ 16. Physical abuse by the mother } \\
\hline \multicolumn{6}{|l|}{ 17. Both parents' failure to fulfill their promises } \\
\hline \multicolumn{6}{|l|}{ 18. Mother's discrepancy } \\
\hline \multicolumn{6}{|l|}{ 19. Father's neglect } \\
\hline $\begin{array}{l}\text { 20. Insufficient time dedicated by the father to } \\
\text { the child's play }\end{array}$ & & & & & \\
\hline
\end{tabular}


Cronbach's alpha coefficient of internal consistency for the entire sample of examinees was $\alpha=.80$. For the subscale of the assessment of the mother's behaviour, which includes 10 items, the reliability coefficient was $\alpha=.89$. For the subscale of the assessment of the father's behaviour, which also includes 10 items, the reliability coefficient was $\alpha=.88$.

\section{Procedure}

After getting approval from the competent authority, juvenile delinquents inquiry was conducted on several occasions at the Centre for Social Welfare of the Municipality of Podgorica and the Institute for Upbringing and Education "Ljubović" in Podgorica. The main reason for a relatively long period of data collection was the incompliancy (irregular treatment attendance) of juveniles who were sentenced to increased supervision. After explaining the purpose of the inquiry, guaranteeing confidentiality and motivating participants to cooperate, they were inquired. At the beginning of the hour provided for the survey, the filling in of the questionnaire was explained clearly and loudly to examinees, and then clarified in details. They filled in the questionnaire by themselves, under the conditions of individual examination. The inquiry of one examinee took about an hour. Juvenile delinquents often gave explanations of answers in the questionnaires and requested clarifications of specific questions, which prolonged the time of inquiry.

\section{Results}

\section{The results of ANOVA}

The results of ANOVA of 20 variables from the survey (processed in SPSS 10.0) are presented in Table 2. Using ANOVA, we confirmed that each variable is discriminative itself. F-test showed that the differences between the means of almost all variables in these groups were highly significant. The exeption was the variable characterizing mother's complaisance, for which the difference between the means in both groups was less, but still statistically significant (Table 2).

For 19 of 20 variables (except mother's complaisance) the differences between the means in both groups were highly significant $(\mathrm{p}=0.000)($ Table 2$)$.

The values of the studied variables and their variability for delinquents were considerably higher than ones for well-socialized adolescents. Taking into account coefficient $\mathrm{F}$, the most robust difference between the groups was observed for father's neglect dimension. The significance of the differences between arithmetic means for the studied groups proved with t-test, was 
assumed as a basis for the second hypothesis testing and for analysis of the results. The hypothesis (B) that the perception of parental behaviour in delinquent group and in the group of adolescents with socially acceptable behaviour will significantly differ has been confirmed and proved to be correct for all variables.

Table 2 - The results of ANOVA

\begin{tabular}{|l|c|c|c|c|c|}
\hline Variable & Wilks's lambda & $\mathbf{F}$ & $\mathbf{d f 1}$ & $\mathbf{d f 2}$ & p-value \\
\hline Both parent's play with the child & 0,399 & 396,197 & 1 & 263 & 0,000 \\
\hline $\begin{array}{l}\text { Abandonment of the child by both parents } \\
\text { during several days }\end{array}$ & 0,421 & 362,338 & 1 & 263 & 0,000 \\
\hline $\begin{array}{l}\text { Parents' manipulative behaviour towards } \\
\text { the child }\end{array}$ & 0,309 & 588,162 & 1 & 263 & 0,000 \\
\hline Physical abuse by both parents & 0,332 & 528,314 & 1 & 263 & 0,000 \\
\hline Physical abuse by the father & 0,412 & 375,751 & 1 & 263 & 0,000 \\
\hline Physical abuse by the mother & 0,439 & 335,541 & 1 & 263 & 0,000 \\
\hline Mother's severity & 0,642 & 146,712 & 1 & 263 & 0,000 \\
\hline Father's severity & 0,569 & 199,120 & 1 & 263 & 0,000 \\
\hline Mother's complaisance & 0,969 & 8,535 & 1 & 263 & $\mathbf{0 , 0 0 4}$ \\
\hline Father's complaisance & 0,895 & 30,700 & 1 & 263 & 0,000 \\
\hline $\begin{array}{l}\text { Insufficient time dedicated by the father } \\
\text { to the child's play }\end{array}$ & 0,402 & 391,524 & 1 & 263 & 0,000 \\
\hline $\begin{array}{l}\text { Insufficient time dedicated by the mother } \\
\text { to the child's play }\end{array}$ & 0,400 & 394,366 & 1 & 263 & 0,000 \\
\hline Child as a "burden" to the mother & 0,537 & 227,030 & 1 & 263 & 0,000 \\
\hline Mother's emotional detachment & 0,582 & 188,746 & 1 & 263 & 0,000 \\
\hline Child unwanted by the mother & 0,646 & 144,207 & 1 & 263 & 0,000 \\
\hline Mother's indifference & 0,572 & 197,055 & 1 & 263 & 0,000 \\
\hline Mother's discrepancy & 0,572 & 196,530 & 1 & 263 & 0,000 \\
\hline Both parents' failure to fulfill their promises & 0,417 & 368,143 & 1 & 263 & 0,000 \\
\hline Mother's neglect & 0,380 & 429,616 & 1 & 263 & 0,000 \\
\hline Father's neglect & 0,253 & 777,491 & 1 & 263 & 0,000 \\
\hline
\end{tabular}


Results of discriminant function analysis

We ran discriminant analysis for 20 variables (which were subjected to ANOVA before) for the both groups. Since the research included two independent samples, one common descriminant function was detemined. The analysis showed that this function maximally distinguishes the group of delinquents from well-socialized adolescents. The discriminant function itself was characterized by high discriminative power and significance rate $(\mathrm{p}=0.000)($ Table 4$)$.

The value of the characteristic roots $(\lambda=8.487)$ and canonical correlation coefficient $(\mathrm{R}=0.946)$ was tested with $\chi^{2}$-test, which confirmed high statistical significance of the difference between control and experimental groups. Canonical correlation between the set of variables and variable clustering was high $(\mathrm{R}=0.946)$. The high value of the canonical correlation coefficient attests to high discriminative power of that function. Wilks's lambda was 0.105 , its significance was confirmed $\left(\chi^{2}=569,37\right)$ (Table 3$)$. The difference between the group of delinquents and the group of well-socialized adolescents was at a very high level of statistical significance as can be seen from the matrix ${ }^{1}$ of the common discriminant function structure (Table 4).

Table 3 - Canonical discriminant function coefficient, eigenvalue, Wilks's Lambda and $\chi^{2}$ value

\begin{tabular}{|c|c|c|c|c|c|c|c|}
\hline Function & Eigenvalue & $\%$ of variation & $\begin{array}{c}\text { Canonical } \\
\text { correlation }\end{array}$ & $\begin{array}{c}\text { Wilks's } \\
\text { Lambda }\end{array}$ & $\chi^{\mathbf{2}}$ & $\mathbf{d f}$ & $\mathbf{p}$-value \\
\hline 1 & 8,487 & 100,0 & 0,946 & 0,105 & 569,37 & 20 & 0,000 \\
\hline
\end{tabular}

The results obtained by discriminant analysis showed, that total discriminance of the variables is high. In further analysis, we aimed to examine which of the variables are the most discriminative for the groups. Conventionally, we have set the values above 0,400 as significant load of the matrix of discriminant function structure (Table 4).

The most discriminative variables were:

- Father's neglect $(0,590)$

- Parents' manipulative behaviour towards the child $(0,513)$

- Physical abuse by both parents $(0,487)$

- Mother's neglect $(0,439)$

- Both parent's play with the child $(0,421)$

- Insufficient time dedicated by the mother to the child's play $(0,420)$

- Insufficient time dedicated by the father to the child's play $(0,419)$

- Physical abuse by the father $(0,388)$

- Both parents' failure to fulfill their promises $(0,406)$

- Abandonment of the child by both parents during several days $(0,403)$ 
Ten variables were selected by discriminant fuction, other variables (physical abuse by the father, child as a "burden" to the mother, father's severity, mother's indifference, mother's emotional detachment, mother's discrepancy, mother's severity, mother's and father's complaisance). Relatively close to the target value of 0.400 was the variable describing physical abuse by the father (Table 4). The following variables are charachterized by the lowest discriminative power: mother's and father's complaisance, child unwanted by the mother. Taking into account the results of discriminant analysis, we can coclude that under-aged delinquents were more often abandoned for several days by both parents, more frequently subjected to verbal punishment with no reason and physical abuse from both parents, perceived father's and mother's neglect, frustration in meeting their needs, and disappointment at parental promises compared to well-socialized adolescents.

Table 4 - Structure matrix and standardized coefficients of canonical discriminative function

\begin{tabular}{|l|c|c|}
\hline Variable & ${ }^{*}$ Function $\mathbf{1}$ & ${ }^{* *}$ Function $\mathbf{1}$ \\
\hline 48. Father's neglect & 0,590 & $-0,473$ \\
\hline 31. Parents' manipulative behaviour towards the child & 0,513 & 0,110 \\
\hline 32. Physical abuse by both parents & 0,487 & $-0,109$ \\
\hline 47. Mother's neglect & 0,439 & 0,370 \\
\hline 29. Both parent's play with the child & 0,421 & 0,090 \\
\hline 40. Insufficient time dedicated by the mother to the child's play & 0,420 & 0,102 \\
\hline 39. Insufficient time dedicated by the father to the child's play & 0,419 & 0,147 \\
\hline 33. Physical abuse by the mother & 0,410 & 0,214 \\
\hline 46. Both parents' failure to fulfill their promises & 0,406 & 0,204 \\
\hline 30. Abandonment of the child by both parents during several days & 0,403 & $-0,006$ \\
\hline 34. Physical abuse by the father & 0,388 & 0,267 \\
\hline 41. Child as a "burden" to the mother & 0,319 & 0,218 \\
\hline 36. Father's severity & 0,299 & $-0,120$ \\
\hline 44. Mother's discrepancy & 0,297 & 0,225 \\
\hline 45. Mother's severity & 0,297 & 0,095 \\
\hline 42. Mother's emotional detachment & 0,291 & $-0,202$ \\
\hline 35. Mother's severity & 0,256 & 0,034 \\
\hline 43. Child as a "burden" to the mother & 0,254 & 0,140 \\
\hline 43. Father's complaisance & $-0,117$ & 0,000 \\
\hline 38. Mother's complaisance & $-0,062$ & 0,110 \\
\hline
\end{tabular}

* Correlational coefficients of the variable and common discriminant function

* * Standardized coefficients of canonical discriminant function 
The results of discriminant analysis showed that father's neglect variable is characterized by the utmost discriminative power, while parents' manipulative behaviour towards the child ranked second. Relatively low power of the other seven variables did not point on the structural differences, which might have had considerable predictive value. These variables should be interpreted more as feasible trends, than how a reliable diagnostic markers in sociology.

\section{Discussion}

\section{Father's neglect}

Neglect by the father is the most discriminating dimension of the research. The results of our study showed that in terms of perceived parental behaviour on the dimension of father's neglect participants of the experimental and control groups significantly differ. Delinquents perceive their fathers as emotionally indifferent, disinterested, showing irresponsibility for the child. Significantly higher results in the experimental group confirmed that the reason of neglect is not the nature of the father-to-son type of relationships which are antagonistic themselves, but that there are some abnoramalities in the relationships between father and children in the families of delinquents.

In terms of the gender, we found that male juvenile delinquents more often perceived father's neglect during childhood, than female ones. Our findings indicate the importance of the relationship with the father especially when juvenile delinquents are involved. The effect of the negative attitude of the father on the behaviour of the son is more robust than on daughter's behaviour. Even when the emotional relationships with the mother is not negative, hostility from the father's side increases the risk of the development of aggressive behaviour patterns in sons. Father plays a key role in the process of identifying a male child with a person of the same sex. Interaction between the boy and his father is associated with the identification with his own gender, adopting masculine roles and behaviour patterns in accordance to this role. However, the situation when the father leaves the family and his children or looks after them inadequately often complicates the identification process, which is considered to be the crucial part of socialization.

Father's neglect in the families of juvenile delinquents (experimental sample) in the period of their early childhood can be explained by the fact that in $51 \%$ of cases they come from families alcohol dependent fathers. Fathers of the delinquents in the majority of these cases were the only members with an alcohol abuse in the family. Father's alcoholism led to disorders of emotional relations among family members and created a cold and loose emotional relationship between a father and child. The children 
percieve anger, rage, rejection from the side of the parents, they feel isolated and abandoned. Dissemblance of hurt and anger, especially towards father during childhood leads to aggressive behaviour towards the environment during adolescence.

Neglect of juvenile delinquents from the father's side during childhood, probably is our most interesting result of our research, which was not mentioned previously in foreign studies. In the majority of other research articles the importance of father's physical aggression in the development of behavioural disorders in children is empahsized (Patterson et al., 1992; Kashani et al., 1998). Findings from our research points on the cultural specificity of our population and the traditional patterns of behaviour, in which the community is tolerant to fathers, and, in particular, fathers of illegitimate children. Sometimes they are immune from any responsibility for the child.

Parents' manipulative behaviour towards the child (verbal agression)

The dimension of parents' manipulative behaviour towards children, which measures the level of verbal aggression is also important for the definision of the common discriminant function. We found out that adolescents with socially acceptable behaviour claimed verbal aggressiveness just in a small number of cases. In contrast, juvenile delinquents percieved distinct verbal aggressiveness from parents' side, and characterize their relationships with both parents as very problematic. By the analysis of the results, we found that parents' verbal aggression in families of juvenile delinquents is a significant predictor of children's behaviour. Parents' verbal aggressiveness towards children is a part of the inconsistent disciplinary practices of parents.

Parents' manipulative behaviour towards children, i.e., verbal aggression, can be explained by the lack of parental confidence in relationships with children or by the feeling that the child is unwanted, especially by mothers. Mother who percieve her child as a "burden" considers care of him as imposed and unpleasant obligation she is also prone to criticize the child and imposes numerous requirements. Verbal punishment is not reasoned with an explanation of guilt, so it does not accomplish its feedback function. Repeated criticism, humiliation, underestimation, ridicule exert bad influence on a child's development, lead to a formation of low self-esteem; through that children are taught lies, sarcasm, and aggression; the insults that were internalized form distorted self-portret, they consider themselves as bad and stupid. Such pronounced emotional distance between parents and their children does not satisfy children's need for love and attention. Instead of this, their behaviour becomes aggressive due to frustration caused by manipulative attitude of parents. Children defend themselves from parental pressure by becoming hyperactive and by developing other behavioural problems. 
Our findings are consistent with the results of empirical research of Barber (Barber et al., 1996, pp. 3296-3319). Barber hypothesized that exposure to psychological violence through parental criticism and verbal aggression is an important predictor of externalizing (outward aggression) and internalizing (inward aggression) problems (Barber et al., 1996, p. 3310).

\section{Physical abuse of the child (both parents)}

By the analysis of the results we found that juvenile delinquents in our sample perceive their parents as physically aggressive, emotionally cold significantly more often than ones from the control group who, in majority, perceive their parents as emotionally warm. As for the mother, 53\% respondents of experimental group agreed with the statement My mother loves me more than my father. Based on this, we concluded that delinquents perceived their mothers ambivalently: at the same time, as emotionally warm and aggressive.

Since this attitude is especially pronounced in male participants, this can be explained by a more intimate relashionships between mothers and their sons, which is additionally stimulated by fear of losing mother's love. The result obtained by this research may be one of the most interesting because it charecterizes the cultural specificity of montenegrin population, and was not presented before in foreign studies. Men's brutality in intimate relations with their wives makes women to seek the compensation for that in emotional attachment to male children and complaisance towards their sons.

We found that the majority of juvenile delinquents comes from the families with multiple social pathology as following: father's alcoholism, incomplete family (death of one parent or divorce), poverty, mental disorders, quarrels and fights between parents, suicide. Of all these pathological manifestations the most pronounced were father's alcoholism and fights between mother and father. Physical abuse in the relationships between the parents of the delinquent plays an important role in the formation of the distorted model of marital relationships, which he will bring into his future life and which will later express itself in aggressiveness and sadomasochistic relationships.

Since the majority of the delinquents comes from the middle class families, which have partly lost patriarchal family structure typical for lower working class, wifes in these families might straightly disagree with husband's decisions, the opposition of the mother to father's authority is more transparent to the children. In these situations, the father loses authority, that leads to quarrels and fights between parents. The loss of paternal authority 
can be partly conditioned by his failure to educate children due to inadequate disciplinary measures. Aggressive behaviour of parents induces hostility and aggression in children. Restraint of anger towards parents induces aggressive behaviour towards the environment in a form of aggression towards peers and things. Delinquencies that occur in adolescence may be a consequence of unrealized aggression towards family members.

Our findings are consistent with the results of numerous studies (Mc Cord, Mc Cord, 1959; Bennett, 1960; Glueck, Glueck, 1970; Patterson et al., 1992, by Hrnčić, 1996) indicating that the inconsistent disciplinary measures with corporal punishment important are significant predictors of delinquency.

\section{Conclusion}

The study was focused on parental acceptance/rejection of children during early childhood and its impact on the development of the delinquent behaviour. We were looking for an answer to a question which characteristics of perceived parental behaviour differentiate juvenile adolescents from ones with socially acceptable behaviour.

The hypothesis concerning significant differences between the experimental and control groups in terms of perceived behaviour of parents was accurate. The analysis of the difference between the experimental and control groups in terms of the perceived parental behaviour showed that father's neglect, parents manipulative behaviour towards children (verbal aggression) and physical abuse by both parents have the greatest predictive value for the development of delinquency. This finding was not presented previously in foreign studies and emphasizes cultural specificity of montenegrin population.

The analysis concerning physical abuse by both parents showed that juvenile delinquents more often perceive physical abuse by both parents, than participants of the control group. The interesting fact is the discordance inside the experimental group in terms of the gender: data analysis showed more robust effect of the negative relationships with his father on the behaviour of the son, than on daughters' behaviour.

We also found that significantly more often the parental rejection is more often percieved by juvenile delinquents, than by well-socialized adolescents. The results of our study suggest that parental actions towards children in the period of early childhood are of crucial importance for the development of delinquent behaviour in adolescence. These results provide a basis for a conclusion that there is a correlation between the acceptance of children in the family and delinquency in adolescence. 
The differences between the groups indicate the need for a specific approach to the prevention and treatment of these problems. For more detailed research of this issue and evaluation of the results of our research we need to thoroughly develop long-term research methodology for all kinds of family relations. Our research showed that the exchange of the data and experience between the institutions of the criminal justice process and institutions of social protection is not only justified but also necessary in working with troubled adolescents. 